\title{
When Regulating Emotions at Work Pays Off: A Diary and an Intervention Study on Emotion Regulation and Customer Tips in Service Jobs
}

\author{
Ute R. Hülsheger \\ Maastricht University
}

Anna F. Schewe
Bielefeld University

\author{
Jonas W. B. Lang \\ Ghent University
}

Fred R. H. Zijlstra

Maastricht University

\begin{abstract}
We investigated the relationship between deep acting, automatic regulation and customer tips with 2 different study designs. The first study was a daily diary study using a sample of Dutch waiters and taxi-drivers and assessed the link of employees' daily self-reported levels of deep acting and automatic regulation with the amount of tips provided by customers $(N=166$ measurement occasions nested in 34 persons). Whereas deep acting refers to deliberate attempts to modify felt emotions and involves conscious effort, automatic regulation refers to automated emotion regulatory processes that result in the natural experience of desired emotions and do not involve deliberate control and effort. Multilevel analyses revealed that both types of emotion regulation were positively associated with customer tips. The second study was an experimental field study using a sample of German hairdressers $(N=41)$. Emotion regulation in terms of both deep acting and automatic regulation was manipulated using a brief self-training intervention and daily instructions to use cognitive change and attentional deployment. Results revealed that participants in the intervention group received significantly more tips than participants in the control group.
\end{abstract}

Keywords: emotional labor, tips, intervention, deep acting, automatic regulation

Three decades ago, Hochschild (1983) drew scientific attention to the fact that many employees need to manage their emotions as part of their job, and she coined the term "emotional labor" for this type of work. Hochschild suggested that employees typically use two different strategies — surface and deep acting — to modify their emotions in work situations in which their emotions do not match the emotional requirements of their job. Service workers who perform deep acting modify their inner emotions and feelings to meet the emotional display requirements of their work situation. Deep acting results in authentic displays of emotion because employees alter their true feelings (Grandey, 2000). In contrast,

This article was published Online First November 10, 2014.

Ute R. Hülsheger, Department of Work and Social Psychology, Faculty of Psychology and Neuroscience, Maastricht University; Jonas W. B. Lang, Department of Personnel Management, Work and Organizational Psychology, Faculty of Psychology and Educational Sciences, Ghent University; Anna F. Schewe, Department of Work and Organizational Psychology, Faculty of Psychology and Sports Sciences, Bielefeld University; Fred R. H. Zijlstra, Department of Work and Social Psychology, Faculty of Psychology and Neuroscience, Maastricht University.

We are grateful to Suzanne Bouwman and Jan Dolezal for their help in collecting data for Study 1 and to Anne-Katrin Hardt for her help in collecting data for Study 2.

Correspondence concerning this article should be addressed to Ute R. Hülsheger, Department of Work and Social Psychology, Faculty of Psychology and Neuroscience, Maastricht University, P.O. Box 616, 6200 MD Maastricht, The Netherlands. E-mail: ute.hulsheger@maastrichtuniversity.nl service workers who engage in surface acting only modify and manage their emotional expressions without changing their inner emotions and feelings. Surface acting accordingly leads to the display of faked emotions (cf. Grandey, 2000), and surface acting is commonly considered to be problematic because the faking of emotions requires high effort, and because many customers are able to distinguish between faked and authentic emotions (Groth, Hennig-Thurau, \& Walsh, 2009).

Researchers have recently supplemented Hochschild's basic distinction between deep and surface acting by a third form of emotion regulation-automatic regulation. Automatic regulation is similar to deep acting in that it also involves the authentic display of desired emotions (Beal \& Trougakos, 2013; Diefendorff, Croyle, \& Gosserand, 2005; Martinez-Inigo, Totterdell, Alcover, \& Holman, 2007). Furthermore, both deep acting and automatic regulation are antecedent-focused forms of emotion regulation that occur before an emotion has fully developed (Gross, 1998). In contrast to deep acting, however, automatic regulation refers to the spontaneous experience and expression of organizationally desired emotions and does not involve conscious "acting" (Martinez-Inigo et al., 2007). Automatic regulation has therefore also been referred to as the expression of naturally felt emotions (Ashforth \& Humphrey, 1993; Diefendorff et al., 2005). Although automatic regulation does not involve a deliberate effort to change emotions, emotion researchers have suggested that it is a form of emotion regulation (Mauss, Bunge, \& Gross, 2007; Mauss, Bunge, \& Gross, 2008; Mauss, Evers, Wilhelm, \& Gross, 2006; Mikolajczak, Tran, Brotheridge, \& Gross, 2009). The reason is that in the 
context of the emotions literature the term regulation refers to changes to emotional response tendencies and these changes can be initiated not only by deliberate, controlled processing (i.e., deep acting) but also by automatic processing involving less effort and control (i.e., automatic regulation; Mauss et al., 2008).

Research on the consequences of emotional labor for the wellbeing of service workers (for a meta-analytic review see Hülsheger \& Schewe, 2011) as well as for customer service evaluations (e.g., Grandey, Fisk, Mattila, Jansen, \& Sideman, 2005; Groth et al., 2009) has been burgeoning in the last decades. Considerably less research has addressed the relation between emotional labor strategies and customer behavior, such as financial compensation for service workers in the form of tips (however, see Chi, Grandey, Diamond, \& Krimmel, 2011 for a recently published study). This relative lack of research on the role of emotional labor in actual customer behavior is surprising because most organizations operating in the service sector seem to believe that emotional displays have a strong effect on customer behavior, and they therefore seek to regulate and improve the emotional display of their service employees by implementing emotional display rules (Rafaeli \& Sutton, 1987).

In the present research, we focus on the implications of deep acting and automatic regulation for customer behavior and investigate the relationship between employees' emotion regulation and customer tips across several days in different service occupations where employees typically receive tips (waiters, taxi drivers, hair dressers). We build on the emotion as social information model (EASI; Van Kleef, 2009) and ego depletion theory (Baumeister, Bratslavsky, Muraven, \& Tice, 1998; Muraven, Tice, \& Baumeister, 1998) and suggest that deep acting and automatic regulation are positively related to customer tips. We tested these ideas in two studies. Study 1 was an observational diary study linking reports of deep acting and automatic regulation to service workers' daily amount of tips. Study 2 was a randomized field experiment, in which we studied the effects of a self-training intervention designed to train deep and automatic emotion regulation strategies. We examined the effectiveness of this intervention by comparing the amount of customer tips in the self-training group with the amount of tips received by the control group.

Our research makes three contributions to the literature. Our first contribution is that we investigate the relationships of deep acting and automatic regulation with customer tips using eventsampling methodology (Study 1). As noted previously, research on the role of emotional labor for customer behavior, such as financial compensation (e.g., tips), is rare, and a notable exception is the work of Chi and colleagues (2011). They investigated how stable between-person differences in deep acting and surface acting interact with extraversion in predicting customer tips. Our use of event-sampling methodology in Study 1 extends Chi et al.'s (2011) work by linking daily fluctuations and within-person (state) variation in emotional labor strategies to customer tips. Investigating emotional labor strategies at the within-person level is important because the emotional labor literature suggests that emotion regulation is a dynamic construct that should vary within individuals. According to emotional labor theory, emotion regulation is a reaction to a mismatch between felt and required emotions that occurs during employee-customer interactions (Grandey, 2000; Holman, Martinez-Inigo, \& Totterdell, 2008; Hülsheger \& Schewe, 2011). The frequency and intensity of such mismatches depends on variable factors, for instance on an employee's preexisting state of mood, on the busyness of the store, the stress-level of an employee, and on the degree to which employees experience difficult transactions with customers. Supporting these ideas, empirical research has revealed that about $30 \%$ to $40 \%$ of variation in deep acting lies within persons (Judge, Woolf, \& Hurst, 2009; Schreurs, Guenter, Hülsheger, \& van Emmerik, 2014; Scott \& Barnes, 2011). It has therefore been argued that in order to fully capture the role of emotion regulation in the workplace, one needs to understand how emotion regulation functions at the most basic, the within-person level (Beal \& Trougakos, 2013).

The second contribution of our research is that we study the relationship between automatic regulation and customer behavior in the form of customer tips. Researchers have long acknowledged the existence of automatic forms of emotion regulation, and have suggested that automatic regulation can also result in desired emotional displays (e.g., Beal \& Trougakos, 2013; Cropanzano, Weiss, \& Elias, 2004; Diefendorff et al., 2005; Kruml \& Geddes, 2000). However, the relationship of automatic regulation with performance outcomes in general and with customer behavior in particular has, to date, not yet been empirically addressed in the literature. We therefore believe that it is important to study automatic regulation and consider it jointly with deep acting in seeking to understand effective emotion regulation in the workplace.

Our third contribution is that this is the first study of which we are aware that uses an experimental manipulation of emotion regulation strategies in a field setting (Study 2). An experimental manipulation has the potential to yield valuable insights into causality and additionally provides an important step towards emotion regulation intervention research.

\section{Deep Acting and Automatic Regulation}

Employees' conscious effort to align their actual feelings with organizational and occupational display rules has mostly been referred to simply as deep acting (Grandey, 2000; Grandey et al., 2005; Hennig-Thurau, Groth, Paul, \& Gremler, 2006). More specifically, however, it has been labeled active deep acting by previous researchers (Cropanzano et al., 2004; Kruml \& Geddes, 2000). Because active deep acting involves conscious attempts to alter emotions internally, it results in authentic emotion displays. Researchers have theoretically distinguished this conscious, effortful form of emotion regulation from a more unconscious, effortless way of regulating and experiencing organizationally desired emotions (Beal \& Trougakos, 2013; Cropanzano et al., 2004; MartinezInigo et al., 2007). The latter has initially been referred to as passive deep acting (Cropanzano et al., 2004; Zapf, 2002). Researchers now use the term expression of naturally felt emotions (p. 339; Diefendorff et al., 2005; see also Ashforth \& Humphrey, 1993) or automatic (emotion) regulation (Beal \& Trougakos, 2013; Martinez-Inigo et al., 2007). To refer to this type of automatic antecedent-focused emotion regulation, we use the term "automatic regulation" in the remainder of this article. Not only emotional labor, but also fundamental emotion researchers have argued that emotion regulation can be performed automatically. Drawing on dual-process models in social and cognitive psychology, Mauss and colleagues (2007) argued that emotion regulation can be processed in a deliberate or in an automatic fashion. While deliberate processing requires explicit goals and attentional resources, 
automatic processing is triggered by sensory inputs that activate knowledge structures which, in turn, shape psychological functions (Mauss et al., 2007). Accordingly, automatic emotion regulation has been defined as "changes (either increases or decrease) to any aspect of one's emotion without making a conscious decision to do so, without paying attention to the process of regulating one's emotions, and without engaging in deliberate control" (Mauss et al., 2008, p. 43; see also Gallo, Keil, McCulloch, Rockstroh, \& Gollwitzer, 2009; Mauss et al., 2007; Mauss et al., 2006; Mikolajczak et al., 2009).

Some researchers have speculated that automated emotion regulation processes may, in fact, occur more frequently than deliberative, controlled efforts to regulate emotions (Beal \& Trougakos, 2013). It is all the more surprising that automatic emotion regulation has received little attention in the empirical emotional labor literature (exceptions are Diefendorff et al., 2005; Martinez-Inigo et al., 2007) and has, to our knowledge, neither been linked to performance outcomes nor has it been studied at a within-person level of analysis.

In the emotional labor context, deep acting and automatic regulation bear some similarities: both are antecedent-focused, involve the same strategies (i.e., cognitive reappraisal and attentional deployment; Beal \& Trougakos, 2013) and both yield authentic emotional displays that are in line with organizational display rules. Yet, they clearly differ regarding the level of effort and consciousness involved: In the case of deep acting, the emotional display is the result of a conscious, effortful process of trying to change internal feelings; in the case of automatic regulation, the strategies are nonconsciously activated and performed in an automated way that does not require conscious effort (Beal \& Trougakos, 2013; Mikolajczak et al., 2009). Empirical studies have corroborated the theoretical distinction between deep acting and automatic regulation (Diefendorff et al., 2005; Martinez-Inigo et al., 2007).

\section{Deep Acting, Automatic Regulation, and Service Performance}

Building on the EASI model (Van Kleef, 2009; Van Kleef, De Dreu, \& Manstead, 2010), we argue that deep acting and automatic regulation are both positively related to customer tips. The EASI model focuses on interpersonal functions of emotions and posits that emotional expressions convey information to observers and thereby influence their behavior through inferential and emotional contagion processes: The inferential pathway describes how observers infer information about their interaction partner's feelings, attitudes, and behavioral intentions when observing emotional expressions (Van Kleef, 2009). These inferences guide the observer's affective and behavioral reactions. A frustrated and angry customer who is helped by a service representative expressing understanding and sympathy may infer that her request is taken seriously and that the customer service representative is sensitive and willing to help her with the problem. In addition to the inferential pathway, emotional contagion processes may occur. Emotional contagion describes "the tendency to unintentionally and automatically 'catch' other people's emotions through their facial expressions, vocalizations, postures, or bodily movements" (p. 54; Van Kleef et al., 2010). The positive emotions displayed by a happily smiling customer service employee may thus spread over to the customer. Being in a good mood, the customer may provide favorable customer service evaluations or leave more tip than usual. Transferring the propositions of the EASI model to the emotional labor context suggests that employees' emotional displays influence customer reactions. Although the EASI model has not been tested explicitly in the emotional labor literature, it has received indirect support from a number of studies showing that positive emotional displays are positively associated with customer evaluations (Pugh, 2001; Tsai \& Huang, 2002).

The EASI model further specifies that the strength of inferential and emotional contagion processes is dependent on socialrelational factors, such as "the way the emotion is expressed" (Van Kleef, 2009, p. 187). The authenticity of the emotional display may be seen as such factor that influences the perception of emotional displays and their effects on others (Van Kleef et al., 2010). This idea is in line with empirical findings showing that customers provided more favorable service evaluations when employees' emotional displays were perceived as authentic (Grandey et al., 2005; Hennig-Thurau et al., 2006). As described above, the emotional labor literature suggests that deep acting and automatic regulation both yield authentic emotional displays (Cropanzano et al., 2004). They may thereby both facilitate inferential and affective processes and promote customers' willingness to reward service providers with a tip.

Furthermore, literature on ego depletion (Baumeister et al., 1998) suggests another pathway through which automatic regulation may positively relate to customer tips. The effects of emotional labor strategies on well-being and performance have frequently been explained by the extent to which regulating emotions depletes mental resources (e.g., Holman et al., 2008; Hülsheger \& Schewe, 2011). Accordingly, researchers have posited that deep acting is a regulatory process that involves effort and drains mental resources (Goldberg \& Grandey, 2007; Grandey, 2003; Hülsheger \& Schewe, 2011; Totterdell \& Holman, 2003). In contrast, automatic regulation is an automatic process that does not involve effortful self-regulation. This preserves mental energies and frees up cognitive and attentional resources which can be invested in the completion of core work tasks (cf. Gallo et al., 2009). Customer satisfaction is likely to increase to the extent that core service delivery tasks are completed more effectively and this may be rewarded with a higher tip.

\section{The Present Studies}

Arguments presented above suggest that employees receive more customer tips the more they engage in deep acting and automatic emotion regulation. In a recent study, Chi et al. (2011) already provided empirical evidence for a positive relationship between deep acting and customer tips at the between-person level. We extend this work (a) by considering automatic regulation in addition to deep acting (Studies 1 and 2); (b) by studying relationships at the within-person level (Study 1); and (c) by manipulating emotion regulation strategies in a field experiment (Study 2).

Accordingly, we use event-sampling methodology in Study 1 to investigate how daily variations in deep acting and automatic regulation relate to daily amounts of customer tips.

Hypothesis 1: Deep acting will be positively related to the amount of customer tips received at the end of the work day. 
Hypothesis 2: Automatic regulation will be positively related to the amount of customer tips received at the end of the work day.

Further insights will be gained from Study 2, a field experiment, in which participants in the experimental group will receive a self-training in emotion regulation strategies that are the basis of both deep acting and automatic regulation. Such a set-up bears some advantages over Study 1: Although relationships found in Study 1 may, in part, be explained by reverse causation or recall bias, Study 2 provides more insights into causality by manipulating emotion regulation strategies. Notably, Study 1 and 2 use different operationalizations of emotion regulation at work: While we rely on the traditional self-report scales of deep acting and automatic regulation in Study 1, we use a more novel operationalization in Study 2 by manipulating employees' use of emotion regulation strategies.

Hypothesis 3: Participants receiving a self-training intervention in emotion regulation strategies will receive more tips than participants receiving no self-training.

\section{Study 1}

\section{Method}

Sample and procedure. The sample of this study included a total of 171 daily reports collected from 34 Dutch employees who completed a diary over 5 consecutive work days. The employees ( $44.1 \%$ female, $55.9 \%$ male) held different customer service roles, had a mean age of 30.06 ( $S D$ 12.10), and an average tenure of 4 years ( $S D 4.68$ years). The sample consisted of restaurant waiters $(61.8 \%)$, taxi drivers $(29.4 \%)$, and waiters in bars or cafés $(8.8 \%)$.

To recruit participants, taxi drivers and waiters in bars and restaurants in a midsized Dutch city were approached. A total of 236 diary booklets were distributed, 38 of which were returned resulting in a response rate of $16.1 \%$. This response rate is considerably lower than the mean response rate of 52\% which Anseel, Lievens, Scholleart, and Choragwicka (2010) found as a result of a meta-analysis on response rates in organizational survey research. Yet, while studies included in this meta-analysis relied predominantly on one-time surveys, finding lower response rates in diary studies is not unusual (e.g., Schreurs et al., 2014; Trougakos, Hideg, Cheng, \& Beal, 2014). In diary studies participants have to invest considerably more effort and time than in traditional one-time survey studies. Furthermore, no monetary compensation or other incentives were provided which may have improved the response rate. One participant was excluded from data-analysis because s/he failed to indicate daily amount of tips on all 5 days of the study; three participants were excluded because they stopped participation within the first 2 days. The final sample thus consisted of 34 participants providing a total of 166 diary entries.

Before starting to complete the 5-day diary booklet, participants were asked to answer demographic questions, including age, gender, and their profession. Daily emotion regulation, the amount of tips received, and the busyness of the work day were assessed at the end of work.

Measures. Except for the amount of tips received, all measures were assessed on 5-point rating scales (see Table 1).
Table 1

Means, Standard Deviations, and Intercorrelations for all Study Variables of Study 1

\begin{tabular}{lrrrrrr}
\hline & $M$ & $S D$ & 1 & 2 & 3 & 4 \\
\hline 1. Busyness & 2.89 & 1.12 & - & $.35^{*}$ & .23 & .28 \\
2. Deep acting & 2.62 & .83 & $.16^{*}$ & - & .32 & $.40^{*}$ \\
3. Automatic regulation & 3.61 & .73 & .11 & .11 & - & .26 \\
4. Total amount tips & 30.86 & 32.28 & $.40^{* *}$ & $.29^{* *}$ & $.22^{* *}$ & -
\end{tabular}

Note. Below the diagonal correlations at the day level are displayed (based on uncentered values; $n=166$ ); because nesting of day-level variables in persons is not accounted for in these correlations, significance values should be interpreted with caution; above the diagonal correlations at the person level averaged across the 5 days are displayed $(N=34)$.

${ }^{*} p<.05$. ${ }^{* *} p<.01$.

Deep acting. Daily deep acting was assessed with a Dutch translation of Brotheridge and Lee's (2003) emotional labor scale, consisting of three items. Because this scale is a global, timeinsensitive measure of deep acting, the items were adapted to measure daily levels of deep acting: "Today, I made an effort to actually feel the emotions that I need to display to others," "Today, I tried to actually experience the emotions that I must show," "Today, I really tried to feel the emotions that I have to show as part of my job." Coefficient alpha was computed for each of the five days individually and then averaged, resulting in a Cronbach's alpha of .78.

Automatic regulation. To measure automatic regulation, we used a Dutch translation of Martinez-Inigo et al. (2007) four-item automatic regulation scale and adapted it to the day level: "Today, my emotions matched up with what an efficient interaction with clients demands," "Today, my emotions automatically met job requirements," "Today, my emotions fit with job demands," "Today, my emotions spontaneously coincided with requirements from the interaction with clients." Cronbach's alpha was .87 , on average.

Amount of tips received. To assess the amount of tips received, participants were asked to indicate the total amount of tips they received throughout their workday in Euros. Participants in our sample used various ways to keep track of their tips. For instance, many waiters put the tip they received after every transaction in a separate compartment in their wallet. At the end of the day, they simply needed to count the money in the tip compartment. In some other restaurants and bars electronic billing systems were used in which every drink and meal that is ordered is electronically registered on the account of the respective waiter. At the end of the shift, the waiter hands in the amount of money for which he or she has delivered food and beverages. The remaining money is the amount of tip the waiter received. To make sure that every participant had an easy way to count the amount of tips at the end of the day, we also included a table in the diary in which participants could take a note of customer tips after each transaction, in case they did not work with one of the procedures described above.

Busyness. Busyness of the workday was included as a control variable in order to account for the fact that more tips can be earned on busy work days when more customers are being served. We used a single item asking participants to indicate to what extent their workday was busy in comparison to an average workday. 
Response options ranged from 1 (not at all busy) to 5 (extremely busy).

Analyses. To test our hypotheses we analyzed multilevel random coefficient models using Pinheiro and Bates' (2000) R-package nlme. Although we were only interested in day-level reports, we controlled for the nesting of reports in employees because nonindependence of data caused by nesting in higher-level units (employees in this case) can reduce power (Bliese \& Hanges, 2004) if not accounted for by using appropriate analytical methods, such as random coefficient modeling.

We used two kinds of centering methods that both provide valuable but different kinds of information. First, we computed standardized z-scores $(M=0, S D=1)$ for Level 1 predictor variables before performing multilevel analyses. This corresponds to a grand-mean centering approach but has the advantage of enhancing interpretability of the regression coefficients (cf. West, Aiken, \& Krull, 1996) and providing effect size information. Using this coding scheme, an increase in a predictor variable of one standard unit directly corresponds to the increase in Euros in the outcome variable (tips) per day. The interpretation of the coefficients is analogous to the interpretation of standardized regression coefficients resulting from ordinary regression analysis (see Hox, 2002; Lang \& Lang, 2010; Trautwein, Lüdtke, Marsh, Köller, \& Baumert, 2006). Using this centering scheme, the slope estimate is a mixture of the between- and within-person association between for example, deep acting and customer tips (Enders \& Tofighi, 2007). In order to receive information on the unique within-person associations between deep acting and tips that are independent from any between-person association, we therefore ran the same set of analyses, while centering Level 1 predictors at the person mean, thereby removing all between-person variation. Using this centering scheme, the slope is a pure estimate of within-person relationships (Enders \& Tofighi, 2007).

Before proceeding to test hypotheses, we examined the intraclass correlation coefficient Type I (ICC1; Bliese, 2000; Hox, 2002) for the criterion measure. Analyses revealed an ICC1 of .62, indicating that between-source variance explained $62 \%$ of the variance in the amount of tips received across different measurement occasions and supporting the appropriateness of controlling for the nesting of daily reports in employees.

\section{Results}

Table 2 reveals results for a multilevel model predicting the amount of tips received at the end of the day from daily deep acting and automatic regulation. We controlled for busyness and the type of service job. Specifically, we differentiated between (a) waiters in bars or cafés, (b) waiters in restaurants, or (c) taxi drivers. Differentiating between waiters in bars or cafés on the one and in restaurants on the other hand was important because bars and cafés are more informal than restaurants and different tipping expectations and norms exist. We consequently included two dummy variables, one for participants working in restaurants, the other for participants working as taxi drivers. Dummies were not centered. The intercept consequently indicates the expected outcome for an average employee working in a bar or café.

Regarding control variables, the two dummy variables and busyness evolved as significant predictors of the amount of tips received. Results revealed that restaurant waiters and taxi drivers
Table 2

Multi-Level Model Predicting Customer Tips in Study 1

\begin{tabular}{|c|c|c|c|c|}
\hline & \multicolumn{2}{|c|}{$\begin{array}{l}\text { Level } 1 \text { variables } \\
\text { centered at the } \\
\text { grand mean }{ }^{1}\end{array}$} & \multicolumn{2}{|c|}{$\begin{array}{l}\text { Level } 1 \text { variables } \\
\text { centered at the } \\
\text { person mean }\end{array}$} \\
\hline & Estimate & $S E$ & Estimate & $S E$ \\
\hline \multicolumn{5}{|l|}{ Fixed effects } \\
\hline Intercept & $74.54^{* * *}$ & 12.30 & $79.42^{* *}$ & 13.42 \\
\hline Dummy restaurant & $-44.08^{* *}$ & 13.15 & $-49.88^{* *}$ & 14.35 \\
\hline Dummy taxi & $-54.21^{* *}$ & 14.05 & $-59.16^{* *}$ & 15.30 \\
\hline Busyness & $11.16^{* * *}$ & 1.42 & $10.00^{* * *}$ & 1.29 \\
\hline Automatic regulation & $4.58^{* * *}$ & 1.60 & $6.72^{* *}$ & 2.30 \\
\hline Deep acting & $5.06^{* *}$ & 1.81 & $5.42^{*}$ & 2.37 \\
\hline \multicolumn{5}{|l|}{ Random effects } \\
\hline Intercept $S D$ & 20.00 & & 22.09 & \\
\hline Residual $S D$ & 16.14 & & 16.14 & \\
\hline
\end{tabular}

Note. $\quad N=166$ at the day level and 34 at the person level. Models are random intercept models. ${ }^{1}(M=0, S D=1)$. An increase in a predictor variable of one standard unit therefore directly corresponds to the increase in Euros in the amount of tips received per day. Dummy restaurant was coded as $0=$ bar/café/taxi, $1=$ restaurant. Dummy taxi was coded as $0=$ bar/café/restaurant, $1=$ taxi. $S E=$ standard error.

${ }^{*} p<.05 . \quad{ }^{* *} p<.01$ (two-tailed).

received significantly less tip than waiters working in bars or cafés and that employees received more tips on busy workdays.

Controlling for these potential confounds, deep acting and automatic regulation were significantly related to the amount of tips received at the end of the work day. Overall, one standard deviation increase in automatic regulation and deep acting was associated with about 5 Euros increase in tips, respectively. Similar results emerged when considering purely the within-person associations between emotional labor strategies and tips (results obtained using person-mean centering). Hypothesis 1 and 2 were thus supported: On days that employees reported that they spontaneously felt required emotions (automatic regulation) or manufactured them using deep acting, they earned more tips.

\section{Brief Discussion of Study 1}

Supporting Hypothesis 1 and 2, our study revealed that one standard deviation increase in service workers' daily level of deep acting and automatic regulation was associated with around 5 Euros increase in customer tips, respectively.

Although this study provides valuable first insights into the relationship of deep acting and automatic regulation with customer tips, it also bears a number of limitations: First and foremost, although a diary study has a longitudinal set-up and provides data on the relationship between variables on consecutive work days, analyses on the link between emotional labor strategies and customer tips were cross-sectional and therefore do not allow making causal inferences. Although theory suggests that deep acting and automatic regulation lead customers to provide more tips, the causal ordering may also be reversed. For instance, on days that employees receive more tips than usual, they may be more motivated to engage in deep acting or may have higher emotion regulation self-efficacy and therefore engage in more deep acting and automatic regulation (for a discussion of alternative causal pathways see also Hülsheger, Lang, \& Maier, 2010). Second, emotional labor strategies and customer tips were assessed at the 
same time point. Indicating how much tips they earned on a particular day may have influenced participants' self-reports of deep acting and automatic regulation. If they received a large amount of tips on a given day they might have retrospectively inferred that they engaged in a lot of deep acting and automatic regulation (recall bias). Study 2 was therefore designed to address these shortcomings by extending findings from Study 1 with an experimental set-up.

\section{Study 2}

The goal of Study 2 was to investigate how a self-training intervention in emotion regulation strategies affects customer tips. Study 2 extends Study 1 and earlier emotional labor research. Researchers have repeatedly called for experimental studies in order to shed light on the causal nature of emotional labor-outcome relationships (e.g., Chi et al., 2011; Grandey, 2003; Judge et al., 2009; Scott \& Barnes, 2011). Yet, to date, very few studies have done so (an exception is e.g., Hennig-Thurau et al., 2006) and these were conducted in the laboratory. With Study 2, we respond to this call and investigate whether customer tips can be raised by manipulating emotional labor strategies. A unique element of Study 2 is the integration of an experimental manipulation into a diary study conducted in a field setting, which allows studying intervention effects in a natural work environment.

Study 2 also has potential practical implications. Several researchers have argued that training emotion workers to use adaptive emotion regulation strategies may benefit their performance and well-being and could accordingly be a useful strategy for organizations (e.g., Chi et al., 2011; Grandey, 2003; Grandey et al., 2005; Groth et al., 2009; Hülsheger \& Schewe, 2011; Judge et al., 2009; Rupp, McCance, Spencer, \& Sonntag, 2008). However, research developing and evaluating interventions to enhance emotion regulation skills is still scarce. Study 2 contributes to closing this research gap by providing a first test of the effectiveness of a self-training in emotion regulation strategies.

\section{Goal of the Self-Training Intervention}

The self-training intervention focused on training employees in the use of emotion regulation strategies that are underlying both deep acting and automatic regulation, namely cognitive change (also referred to as cognitive reappraisal) and attentional deployment. The idea that employee deep acting involves cognitive change and attentional deployment is deeply anchored in the emotional labor literature (Grandey, 2000; Groth et al., 2009; Mikolajczak et al., 2009). Cognitive change aims at changing the appraisal of a situation (see Lazarus \& Follkman, 1984), thereby reducing the emotional significance of an event and leading to a different emotional response (Gross, 2008). This can be accomplished by thinking differently about an emotional event itself or about the resources one has to face it (Grandey, 2000; Gross, 2008; Mikolajczak et al., 2009). Attentional deployment refers to changing the experience of emotions by shifting one's attention to specific aspects of the situation (Gross, 2008) or thinking about something that helps stirring up the emotions one needs to experience as part of the job (Grandey, 2000).

Theoretical work in the area of emotion regulation and emotional labor suggests that cognitive change and attentional deploy- ment are also involved in automatic regulation. Fundamental emotion regulation researchers have acknowledged that emotion regulation strategies, including antecedent-focused strategies such as cognitive change and attentional deployment can be automatic and can be processed in the absence of subjective awareness, without deliberate effort and control (Mauss et al., 2007; Mauss et al., 2008; Mikolajczak et al., 2009; Gallo et al., 2009). As a consequence, cognitive change and attentional deployment can be seen as cognitive strategies that are involved in both deep acting and automatic regulation, but with different degrees of effort and automaticity. As Beal and Trougakos (2013) put it “. . . much like the manner in which many other processes move from deliberative, controlled efforts to acquired, automatic skills (Kanfer \& Ackerman, 1989), emotion regulation strategies may attain a certain level of automaticity through repeated use" (Mauss et al., 2007, p. 48).

In designing our emotion regulation self-training, we therefore focused on cognitive change and attentional deployment. To date, studies addressing how emotion regulation in the context of work can be enhanced are rare. An exception is the dissertation from Richard (2003) who linked deep acting to appraisal theories of emotion and trained service employees in using cognitive change. In comparison with employees who received standard customer service training, employees who were taught to cognitively reappraise work situations experienced an increase in positive emotions (e.g., feelings of calm and content) and a decrease in feelings of inauthenticity and depersonalization. However, no training effects were found on job satisfaction, emotional exhaustion, personal accomplishment, and customer satisfaction. As a possible explanation, Richard suggested that the intervention consisted of a single 40-min training session that was delivered off the job and that this may not have been strong enough to produce the expected effects. Specifically, Richard argued that transfer to the work context may have been weak due to a lack of sufficient practice.

In contrast to Richard (2003), the present intervention was not delivered in a single off-the-job training session, but consisted of a self-training that spanned several workdays. In order to enhance transfer and the internalization and automatization of emotion regulation processes, the self-training included the following elements: (a) daily exercises that participants could integrate into their workdays, (b) daily reflections upon these exercises in the evening, and (c) the formulation of implementation intentions. The latter has been shown to increase automation of emotion regulation processes (Gallo et al., 2009).

\section{Method}

The design of the study was a combination of a 10-day diary study and a field experiment with a between subjects design, including a self-training intervention group and a control group. The effects of the intervention were consequently manipulated at the between- person level. A similar design has previously been employed by Totterdell and Parkinson (1999) and Hülsheger, Alberts, Feinholdt, and Lang (2013).

Procedure and sample. To recruit participants, hairdressers working in various shops in North Rhine-Westphalia, Germany, were approached individually at their workplace. The study was presented as a study on emotions and well-being of hairdressers. A total of 98 hairdressers were approached in local hair salons, 62 of 
which initially agreed to participate. They were randomly assigned to one of the two conditions and received a diary booklet; 19 did not return it at all or stopped filling in their diaries within the first days of the study. Forty-three valid diary booklets were returned (19 experimental group, 24 control group; overall response rate $43.9 \%$ ). Two participants were excluded from further analyses because they failed to indicate the amount of tips they earned over the entire study period.

The final sample thus consisted of 41 hairdressers $(n=19$ in the experimental group and $n=22$ in the control group) who completed a total of 409 daily reports. They had a mean age of 29.22 years $(S D=10.8$ years), an average tenure of 11.2 years $(S D=11$ years), and they were predominantly female ( $n=35,85.4 \%$; male: $n=6,14.6 \%)$. With regard to hairdresser rank, 16 participants $(39 \%)$ were master hairdressers (called "Meister," having earned the highest possible degree in German vocational training); 14 (34.1\%) had successfully completed their apprenticeship and were now working as assistant hairdressers; and 11 (26.9\%) were apprentices (trainees) in their first to third year of their apprenticeship. Thirty-seven participants $(90.2 \%)$ were working full-time and four $(9.8 \%)$ were working on a part-time basis. A chi-square test revealed that there were no significant differences between the experimental and the control group regarding gender (chisquare $=1.17, n s)$, hairdresser rank (chi-square $=.23, n s)$, and full- versus part-time employment (chi-square $=.02, n s)$. Furthermore, a multivariate analysis of variance revealed no significant differences between the experimental and the control group regarding age and tenure, $F(2,38)=2.69$, ns.

The self-training intervention. The intervention was delivered in written format and integrated into the diary booklet. The self-training intervention had three key elements: First, a description of emotion regulation techniques at work; second, successive implementation of these techniques during the first 4 days of the study and formation of implementation intentions; third, daily reflections on their strategy use in the evenings.

The first element consisted of a two-page brief introduction to emotion regulation strategies that was provided on the day before participants started filling in the diaries. Specifically, participants were familiarized with three techniques of cognitive change (Grandey, 2000; Gross, 2008; Mikolajczak et al., 2009; Richard, 2003; Totterdell \& Holman, 2003): (a) reappraising difficult situations by considering that offensive client behavior is not meant as a personal assault, but rather reflects the customer's personal problems (reappraisal); (b) reappraising difficult situations by considering them a personal challenge and opportunity for growth (reappraisal); (c) putting themselves in the client's shoes (perspective taking). To train attentional deployment, participants were encouraged to (d) trigger positive emotions by thinking of positive and enjoyable past or future events. Overall, participants were thus familiarized with four specific techniques that facilitate emotion regulation at work.

As part of the second element, these techniques were successively implemented into participants' workdays. The four techniques were redescribed at the end of the morning survey during the first 4 days, one each day. In addition, participants were asked to imagine a typical difficult situation with a customer and to describe how they plan to implement this technique in such a situation during the upcoming workday. To enhance their commitment to actually do so, they were asked to write down their ideas in the diary. This training element was included in order to enhance participants' implementation intentions (Gallo et al., 2009).

Goal of the third element of the intervention was to enhance learning, internalization, and self-regulation by fostering participants' reflection on their daily strategy use (Sitzmann \& Ely, 2010). After filling in the evening surveys, participants were asked to provide a written description of a situation in which they used the technique in question on that specific work day; they were asked to reflect on the effectiveness of their strategyuse and to describe how they could improve their strategy-use in the future.

The central training phase in which participants were familiarized with the four different techniques ended on the evening of the fourth day of the diary study. On the following 6 days, participants were asked to apply the techniques during their work.

Measures. In the first general part of the questionnaire booklet, participants were asked to answer general demographic questions, such as age, gender, tenure, staff level, and full- versus part-time employment. After filling in the general questionnaire, participants started filling in brief diary questionnaires after work (see Table 3).

Except for the amount of tips received, all measures were assessed on 5-point rating scales. All measures were assessed over the entire 10-day period, except for deep acting and automatic

Table 3

Means, Standard Deviations, and Intercorrelations for all Study Variables of Study 2

\begin{tabular}{lrrrrrrr}
\hline & $M$ & $S D$ & 1 & 2 & 3 & 4 & 5 \\
\hline 1. Busyness & 3.17 & .87 & - & .24 & -.14 & .11 & -.12 \\
2. Deep acting & 2.56 & .92 & $.23^{* *}$ & - & .29 & .15 & .18 \\
3. Automatic regulation & 3.05 & .75 & -.08 & .11 & - & .18 & .13 \\
4. Total amount of tips per day & 14.16 & 11.80 & $.22^{* *}$ & .12 & $.23^{* *}$ & - & $.89^{* * *}$ \\
5. Tip per day per client & 1.76 & 1.54 & -.10 & .08 & $.23^{* *}$ & $.77^{* *}$ & - \\
\hline
\end{tabular}

Note. Below the diagonal correlations at the day level are displayed; busyness, and tips were assessed over the entire 10-day period $(n=395-407)$, deep acting and automatic regulation were assessed on the last 4 days of the study $(N=164)$; because nesting of day-level variables in persons is not accounted for in these correlations, significance values should be interpreted with caution; above the diagonal correlations at the person level averaged across all 10 days (busyness, tip)/across the last 4 days (deep acting and automatic regulation) are displayed $(n=40-41)$.

${ }^{*} p<.05$. *** $p<.01$. 
regulation. These were assessed only on the last 4 days of the study in order to avoid sensitization effects and contamination of the control group.

Total amount of tips and tip per client. To assess customer tips, we used two measures. As in Study 1 we assessed the total amount of tips received by asking participants to indicate how much tip they received throughout their workday in Euros. Because participants had individual tip boxes at their workplace, they were able to provide accurate accounts of the amount of tips earned by simply counting the money in their tip box. Furthermore, participants indicated how many clients were served per day, in order to calculate the average tip a hairdresser received per client.

Busyness. As in Study 1, participants indicated the extent to which their workday was busy in comparison to an average workday.

Deep acting. Daily levels of deep acting were assessed with a German translation (Hülsheger et al., 2010) of Brotheridge and Lee's (2003) three-item emotional labor scale. Cronbach's Alpha was .72 , on average.

Automatic regulation. Similarly to Study 1, automatic regulation was measured with items developed by Martinez-Inigo et al. (2007), which were adapted to the day level. To make the diary surveys as short as possible, the third item (see description in Study 1) was dropped because it had high overlap with the second item. On average, Cronbach's alpha was .60.

Self-reported strategy use. After work, participants in the experimental group were asked to indicate how often they applied each of the four regulation techniques (see description of the self-training intervention) on a 5-point scale, ranging from never to very often. An example question is: "How often did you apply the strategy 'Putting myself into the customer's shoes' today?" The control group did not receive this set of questions. Being asked about the use of four specific regulation techniques on a daily basis, participants in the control group may have inferred that using these strategies is desirable, and this would have undermined the experimental set-up of the study.

Analyses. On the last 6 days of the study, participants were instructed to use all emotion regulation strategies that they had learned in the training phase (first 4 days). Participants' reports on these last 6 days were therefore used to test Hypothesis 3. To account for nested data (person level: self-training intervention vs. control group; day level busyness, tip), we performed multilevel analyses using random coefficient modeling with the R-package nlme (Pinheiro \& Bates, 2000). We standardized $(M=0, S D=1)$ all continuous predictor variables, so that an increase of one standard unit in predictor variables corresponds to an increase in Euros in the outcome variables of total amount of tips per day and tips per client.

Intraclass correlation coefficients Type I (ICC1; Bliese, 2000; Hox, 2002) were analyzed for both criterion measures to differentiate between- and within-person variability. Analyses including the last 6 days of the study revealed an ICC 1 of .72 for the total amount of tips received per day and an ICC1 of .75 for tips per client, indicating that between-person variance explained $72 \%$ respectively $75 \%$ of the variance in the amount of tips received across different measurement occasions.

\section{Results}

Compliance check. To inspect whether participants in the self-training intervention group had complied with instructions to train and use cognitive change and attentional deployment, we averaged their daily self-reported strategy-use. A total of 10 participants had values lower than 2 , indicating that they had employed the strategies never (0) or only rarely (1) and had thus hardly participated in the intervention. The remaining nine participants in the intervention group had values equal to or bigger than 2 , indicating that they had participated making use of the regulation strategies from time to time (2), often (3), or very often (4).

Modeling noncompliance. Because training effects can be expected to be weaker or even nonexistent for participants who did not comply with the given instructions, we studied whether compliance moderated the effect of the self-training. Because compliance did not vary in the control group, this variable cannot be treated as a continuous moderator. We therefore modeled compliance with contrast coding in order to test for a potential moderation effect (West et al., 1996). Specifically, we differentiated three groups: compliant participants in the intervention group (with values $>=2$ on self-reported strategy use), noncompliant participants in the intervention group (values $<2$ ), and the control group. Contrast coding is appropriate if a researcher "has specific, a priori hypotheses, that involve linear combinations of two (or more) treatment group means . ." (West et al., 1996, p. 11). According to our hypothesis, one would expect that the intervention is effective for compliant participants in the intervention group rather than for noncompliant participants in the intervention group or the control group. Two contrasts were thus specified following recommendations from West and colleagues (1996): Contrast 1 tested whether the compliant intervention group differed from the noncompliant intervention group and the control group (coded as $2 / 3$ for the compliant intervention group and $-1 / 3$ for the noncompliant intervention group and the control group respectively). Contrast 2 compared the noncompliant intervention group with the control group (coded as 0 for the compliant intervention group, $1 / 2$ for the noncompliant intervention group, and $-1 / 2$ for the control group). According to Hypothesis 3 one would thus expect Contrast 1 to be a significant positive predictor of customer tips.

Main analysis. Results for multilevel models predicting total amount of tips per day and tips per client are depicted in Table 4. Model 1 included busyness as a control variable and tested whether Contrast 1 was significant. The main effect of Contrast 1 was significant for total amount of tips received and tips per client, providing support for Hypothesis 3. Specifically, compliant participants in the intervention group received 14.8 Euros more tips per day and 1.5 Euros more tips per client than participants in the control group and noncompliant participants in the intervention group.

Conducting the same set of analyses using condition (i.e., entire intervention vs. control group) as a predictor instead of the contrasts, yielded somewhat weaker, but the same pattern of significant results. Controlling for busyness, the effect of condition $(0=$ control group, $1=$ intervention group) was $9.20(S E=3.34 ; p<$ 
Table 4

Multi-Level Models Predicting Customer Tips in Study 2

\begin{tabular}{|c|c|c|c|c|}
\hline & \multicolumn{2}{|c|}{ Total amount of tips per day } & \multicolumn{2}{|c|}{ Tips per client } \\
\hline & $\begin{array}{c}\text { Model } 1 \\
\text { Estimate }(S E)\end{array}$ & $\begin{array}{c}\text { Model } 2 \\
\text { Estimate }(S E)\end{array}$ & $\begin{array}{c}\text { Model } 1 \\
\text { Estimate }(S E)\end{array}$ & $\begin{array}{c}\text { Model } 2 \\
\text { Estimate }(S E)\end{array}$ \\
\hline \multicolumn{5}{|l|}{ Fixed effects } \\
\hline Intercept & $16.53^{* * *}(1.62)$ & $16.01^{* *}(1.32)$ & $1.92^{* * *}(.20)$ & $1.86^{* *}(.17)$ \\
\hline Baseline tip & & $6.26^{* *}(1.34)$ & & $0.77^{* * *}(.17)$ \\
\hline Busyness & $2.24^{* * *}(.49)$ & $2.23^{* *}(.50)$ & $-0.11(.06)$ & $-0.13^{*}(.06)$ \\
\hline Contrast 1 & $14.79^{* *}(3.69)$ & $8.68^{* * *}(3.24)$ & $1.51^{* *}(.47)$ & $0.76^{*}(.41)$ \\
\hline Contrast 2 & $2.88(3.68)$ & $2.81(2.99)$ & $0.28(.46)$ & $.26(.38)$ \\
\hline \multicolumn{5}{|l|}{ Random effects } \\
\hline Intercept $S D$ & 9.18 & 7.21 & 1.17 & 0.93 \\
\hline Residual $S D$ & 6.62 & 6.67 & 0.75 & 0.75 \\
\hline
\end{tabular}

Note. $\quad n=231-237$ at the day level and 39-40 at the person level. Models are random intercept models. Predictor variables have been standardized $(M=0, S D=1)$. An increase in a predictor variable of one standard unit therefore directly corresponds to the increase in Euros in the amount of tips received per day. Contrast 1 (coded as $2 / 3$ compliant intervention group, $-1 / 3$ noncompliant intervention group, $-1 / 3$ control group; see West et al., 1996) compares the compliant intervention with the noncompliant intervention and control group; Contrast 2 (coded as 0 compliant intervention group, 1/2 noncompliant intervention group, $-1 / 2$ control group; West et al., 1996) compares the noncompliant intervention with the control group. $S E=$ standard error. ${ }^{*} p<.05$. ${ }^{* *} p<.01$. (In general two-tailed tests were applied; because Hypothesis 3 is a directed hypothesis, Contrast 1 was tested with a one-tailed test of significance.)

$.01)$ for total amount of tips and $.93(S E=.41 ; p<.05)$ for tip per client. $^{1}$

Main analysis controlling for tip at Day 1. A limitation of our design is the fact that we did not assess a no-intervention baseline. Although this design has advantages (Cook \& Campbell, 1979), it cannot rule out preintervention differences in the amount of tips between intervention and control group. However, an analysis including the amount of tip at the first day of the intervention as a baseline did not change the pattern of results. As indicated in Table 4 (Model 2), main effects for the intervention were smaller but remained to be significant.

Similarly, when using condition (i.e., $1=$ intervention vs. $0=$ control group) as a predictor instead of the contrasts, the effect of condition was $5.85(S E=2.63 ; p<.05)$ for total amount of tips and $.52(S E=.33 ; p=.12)$ for tip per client when controlling for tip at Day 1.

Manipulation check. We conducted a manipulation check to test whether the emotion regulation self-training lead to differences in self-reported deep acting and automatic regulation and to assure what Cook and Campbell (1979) refer to as validity of causes and effects. Specifically, we examined whether experimental groups differed on self-reported deep acting and automatic regulation (reported on the last four days of the study). Specifically, we tested two multilevel models predicting deep acting and automatic regulation respectively from Contrast 1 and Contrast 2. As can be seen from Table 5, Contrast 1 had a significant positive effect on automatic regulation, and Contrast 2 was not significant. Results thus indicate (a) that the compliant intervention group reported significantly higher levels of automatic regulation compared to the noncompliant intervention and the control group, and (b) that the noncompliant intervention group did not differ significantly from the control group. Neither Contrast 1 nor Contrast 2 had significant effects on self-reported deep acting. Conducting the same set of analyses using condition (i.e., intervention vs. control group) as a predictor instead of the contrasts yielded no significant differences between the experimental and control group, neither for deep acting, nor for automatic regulation. Taken together, these results suggest that the intervention had some effect on selfreported automatic regulation but not on self-reported deep acting.

\section{Supplementary Analyses}

In addition to our core analyses we conducted a series of supplementary analyses to further analyze and understand our findings and to address potential alternative explanations.

Did tips systematically change over the 10-day period as a function of the intervention? Investigating systematic change patterns in the amount of tips received over the 10-day study period and the extent to which these change patterns differ between intervention and control group may provide further evidence that the effect of the intervention on tip resulted from a training process. We therefore investigated differences between the three groups in change of tips per client across the 10 days in a growth modeling analysis (Bliese \& Ployhart, 2002). Training processes often follow a learning curve which can be characterized by a positive linear (sharp increase in the beginning), a negative quadratic, and a positive cubic trend (continued increase but at a slower rate) at the origin of time (Thoresen, Bradley, Bliese, \& Thoresen, 2004). Growth modeling results revealed that changes in tip in the compliant intervention group between Day 1 and Day 10 were in line with a learning curve (linear: coef. $=.73, p<.05$; quadratic: coef. $=-.20, p<.01$; cubic: coef. $=.01, p<.05)$. In

\footnotetext{
${ }^{1}$ When including hairdresser rank (master, assistant, trainee hairdresser) as an additional control variable, the pattern of results remained the same: Participants in the compliant intervention group received significantly more tips than participants in the noncompliant intervention and the control group (total amount of tips: coef. $=14.58, p<.01$; tip per client: coef. $=$ $1.55, p<.01)$. Similar results emerged when using condition as the predictor instead of the contrasts: total amount of tips: coef. $=8.92, p<$ .01 ; tip per client: coef. $=.90 p<.01$.
} 
Table 5

Multi-Level Models Predicting Deep Acting and Automatic Regulation in Study 2

\begin{tabular}{lcc}
\hline & $\begin{array}{c}\text { Deep acting } \\
\text { Estimate }(S E)\end{array}$ & $\begin{array}{c}\text { Automatic regulation } \\
\text { Estimate }(S E)\end{array}$ \\
\hline Fixed effects & & \\
Intercept & $2.55^{* *}(.13)$ & $3.09^{* *}(.09)$ \\
Contrast 1 & $.19(.29)$ & $.42^{*}(.21)$ \\
Contrast 2 & $-.25(.29)$ & $-.04(.21)$ \\
Random effects & & .46 \\
Intercept $S D$ & .68 & .59 \\
Residual $S D$ & .64 & \\
\hline
\end{tabular}

Note. $\quad N=164$ at the day level and 41 at the person level. Models are random intercept models. Contrast 1 (coded as $2 / 3$ compliant intervention group, $-1 / 3$ noncompliant intervention group, $-1 / 3$ control group; see West et al., 1996) compares the compliant intervention with the noncompliant intervention and control group; Contrast 2 (coded as 0 compliant intervention group, 1/2 noncompliant intervention group, $-1 / 2$ control group; West et al., 1996) compares the noncompliant intervention with the control group. $S E=$ standard error.

${ }^{*} p<.05$. (Because we had a directed hypothesis, Contrast 1 was tested with a one-tailed test of significance.)

contrast, results revealed no significant linear, quadratic, and cubic trend in the control group (coef. $=-.11$, ns; coef. $=.03$, ns; coef. $=.00, n s ;$ respectively) and in the noncompliant intervention group (coef. $=.04, n s ;$ coef. $=-.03, n s ;$ coef. $=.00, n s$; respectively). The differences between the compliant intervention and the noncompliant intervention/control group in linear, quadratic, and cubic change were significant (coef. $=.77, p<.05$; coef. $=-.20, p<.05$; coef. $=.01, p<.05$; respectively) ${ }^{2}$ Change patterns for the three groups are visualized in Figure 1. As depicted in Figure 2, the same pattern of results emerged when we contrasted the original conditions (intervention group vs. control

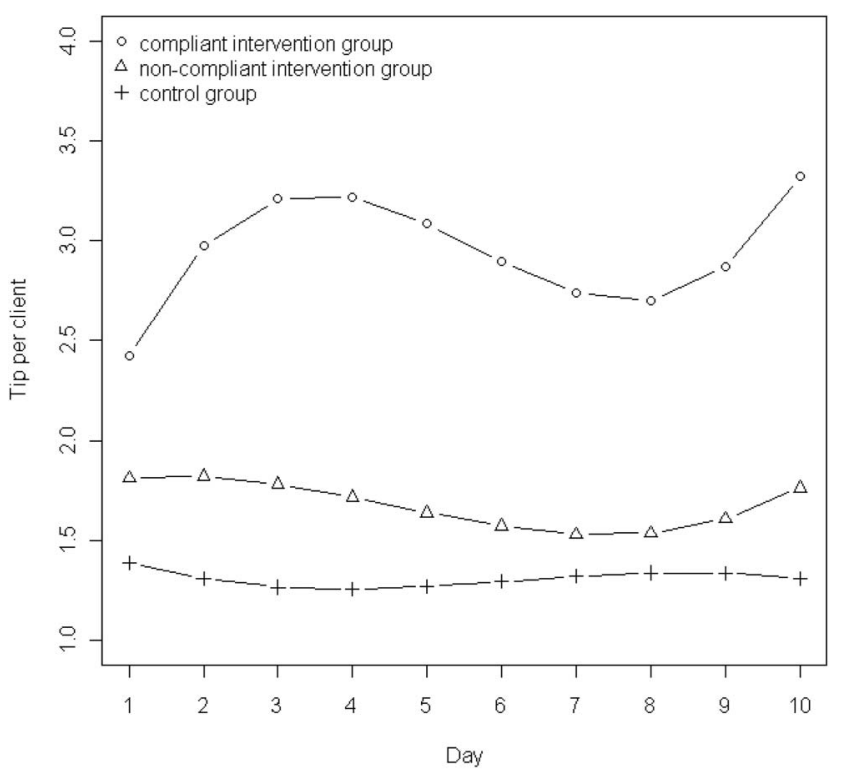

Figure 1. Change patterns in tip per client for the compliant intervention, noncompliant intervention, and control group over the entire 10-day period of the study.

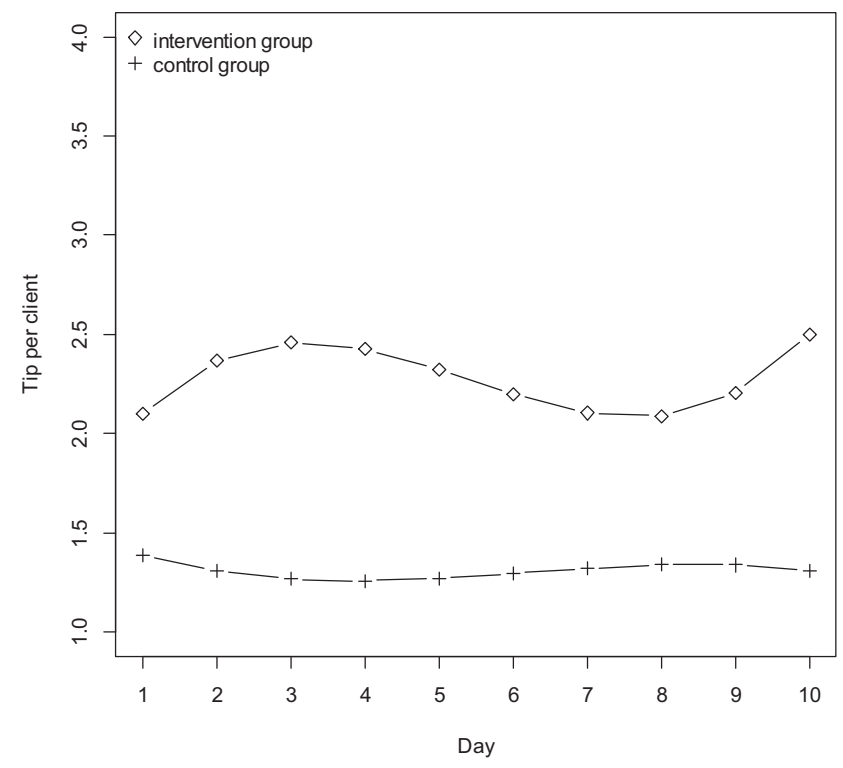

Figure 2. Change patterns in tip per client for the overall intervention and the control group over the entire 10-day period of the study.

group). Taken together, these results suggest that a training process occurred in the compliant intervention group between Day 1 and Day 10 which differed significantly from the change pattern in the noncompliant intervention and the control group.

Did participants' self-reports of deep acting and automatic regulation change as a function of the intervention? As a supplementary analysis to the manipulation check, we investigated change patterns in self-reported deep acting and automatic regulation over the course of the last 4 days by using growth curve modeling. This analysis provides further insights into the effects of the intervention on self-reported deep acting and automatic regulation. Results revealed a positive linear increase in automatic regulation in the compliant intervention group (coef. $=.15, p<$ .05 , one-tailed), but no significant changes in the noncompliant intervention group (coef. $=-.09, n s$ ) or in the control group (coef. $=.04, n s)$. These differences in slopes were statistically significant (coef. $=.18, p<.05$, one-tailed). Regarding deep acting, the compliant intervention group displayed a significant decrease over the last 4 days (coef. $=-.29, p<.01$ ), yet noncompliant intervention (coef. $=-.11, n s$ ) and control group (coef. $=.05, n s$ ) displayed no significant changes. The difference in change patterns between the compliant intervention and the control groups was statistically significant (coef. $=-.27, p<$ $.05)$. Figures 3 and 4 illustrate these change patterns.

How was self-reported strategy use in the intervention group related to customer tips? In the compliance modeling approach in our main analysis we averaged strategy use across days per person to compute the contrasts such that only between-person

\footnotetext{
${ }^{2}$ A similar pattern of results emerged for a growth model with total amount of tip as the dependent variable. In the compliant intervention group, we found linear, quadratic, and cubic effects, significant at the $1 \%$, $5 \%$, and $10 \%$ significance level, respectively. In contrast, linear, quadratic, and cubic trends were not significant in the noncompliant intervention or the control group.
} 


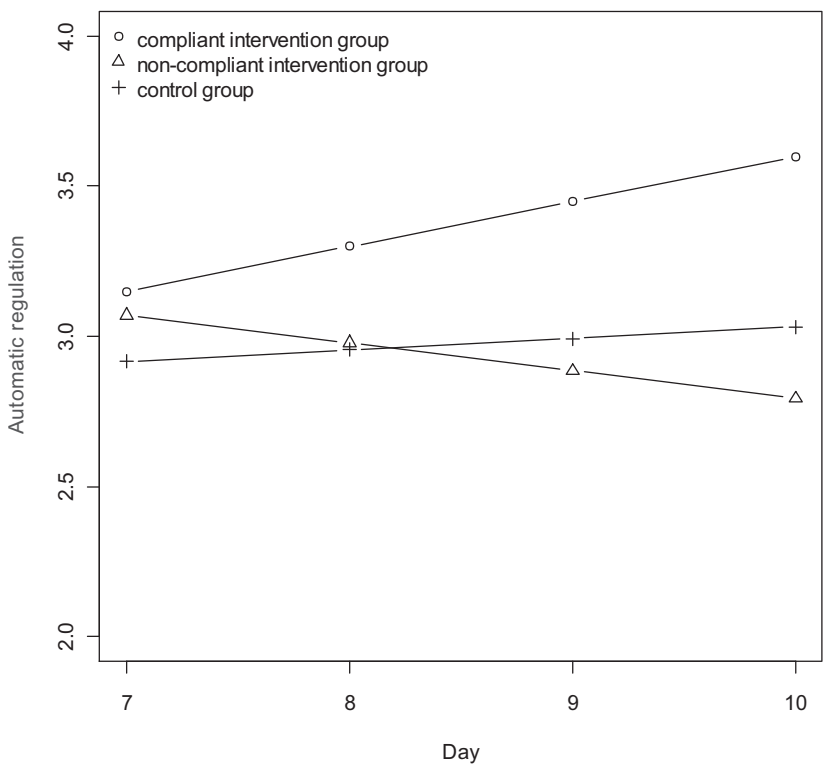

Figure 3. Change patterns in automatic regulation for the compliant intervention, noncompliant intervention, and control group over the last 4 days of the study.

differences in strategy compliance are captured in our main analysis. To investigate whether within-person fluctuations in strategy use contributed meaningfully above and beyond the effects of between-person differences in strategy use, we conducted a supplementary multilevel analysis on the treatment group data. This analysis included between-person effects and within-person effects of strategy use on customer tips, controlling for busyness. The effect of between-person differences in strategy use had a significant effect on tips (total amount of tips: coef. $=6.12, p<.05$; tips per client: coef. $=.67, p<.10)$. Within-person fluctuations in strategy use contributed no additional effect (total amount of tips: coef. $=.06, n s$; tips per client: coef. $=-.08, n s$ ).

What was the relationship between self-reported deep acting and automatic regulation and customer tips in Study 2? Study 2 was designed as a field experiment, focusing on betweenperson differences in customer tips as a function of a self-training intervention. However, because self-reported deep acting and automatic regulation were assessed on the last 4 days of the study, one may wonder whether results of Study 1 were replicated with this data ( $N=157$ observations nested in 40 individuals). As in Study 1, we used busyness as a control variable and self-reported deep acting and automatic regulation as Level 1 predictor variables. Similar to Study 1, automatic regulation was significantly related to tips (total amount of tips: coef. $=2.64, p<.001$; tip per client: coef. $=.36, p<.001)$. In contrast to findings in Study 1 , deep acting was not significantly related to tips (total amount of tips: coef. $=-.35, n s$; tip per client: coef. $=-.11, n s)$. We call for some caution in drawing conclusions from comparisons with Study 1, because Study 1 and Study 2 are based on entirely different study designs: Whereas Study 1 was a purely observational study and measured natural fluctuations in deep acting and automatic regulation, Study 2 was a field experiment and half of the participants received an intervention. As reported in the second supplementary analysis, the intervention in Study 2 led to changes in self-reported deep acting and automatic regulation in the intervention group (see Figures 3 and 4), which may explain the differences in findings regarding deep acting.

\section{Brief Discussion of Study 2}

Our focus in Study 2 was to extend findings from Study 1. Results provided some support for our hypotheses but also left some questions unanswered.

The most important finding of Study 2 was that participants in the intervention group received more tips than participants in the control group. This effect resulted from participants who complied with the instructions of our emotion-regulation self-training because these participants received more tips than both participants in the control group and noncompliant participants in the intervention group. Overall, these findings suggest that providing employees with instructions on how to use cognitive change and attentional deployment strategies helps them to improve their emotional labor effectiveness. The experimental set-up of Study 2 rules out some alternative explanations of the relationships found in Study 1 , such as reverse causation or recall bias.

Although the findings of Study 2 support our main hypothesis (emotion-regulation self-training enhances customer tips), the results of the manipulation check analysis call for some caution in drawing conclusions from the findings of Study 2. In the manipulation check analyses, we found that the compliant intervention group reported higher levels of automatic regulation compared to the noncompliant intervention group and the control group. However, the manipulation check analyses did not reveal any differences between intervention and control or compliant intervention versus noncompliant intervention/control group on self-reported deep acting. One accordingly may wonder whether training deepacting strategies actually led to more deep acting, and whether

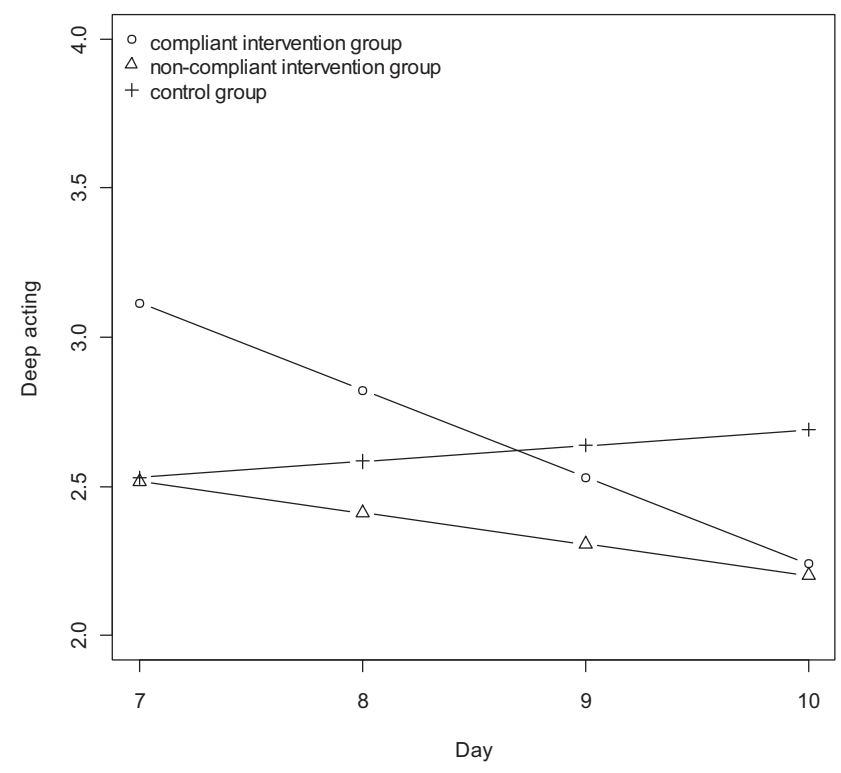

Figure 4. Change patterns in deep acting for the compliant intervention, noncompliant intervention, and control group over the last 4 days of the study. 
actual deep-acting behavior had driven the effects of the intervention on customer tips.

A potential post hoc explanation for the manipulation check findings is that participants in the intervention group, who had complied with instructions and had trained and frequently used emotion regulation strategies in the first 6 days of the study, had reached a level of automaticity that allowed them to regulate their emotions with a minimum of effort. They consequently were able to naturally feel the emotions they had to show as part of their job in the last 4 days (in which self-reported deep acting and automatic regulation were assessed). In other words, training and experience promoted by the intervention may have facilitated automation of emotion regulation processes and participants may have experienced and reported less deep acting, which captures the effort invested in aligning felt and required emotions. This post hoc explanation is in line with Beal and Trougakos' (2013) proposition that emotion regulation strategies ". . . are likely to begin as relatively controlled, deliberative processes, but given some level of consistency in the features of one's work context, may slowly become automatized, requiring little conscious reflection" (Beal \& Trougakos, 2013, p. 39). Our post hoc explanation is also in line with evidence form our second supplementary analysis in which we looked at changes in participants' self-reports of deep acting and automatic regulation in the last 4 days of the study. In this supplementary analysis, we found that the compliant intervention group showed increases in self-reported automatic regulation and decreases in self-reported deep acting across the last 4 days of the study. This pattern of results would be expected when compliant intervention group participants internalized emotion regulation strategies and applied them in an automated fashion toward the end of the study.

This evidence notwithstanding, there may also be alternative explanations. For instance, compliant participants may have been more conscientious and may have reported more automatic regulation in order to please the experimenter. It is generally possible that participants in intervention conditions report higher levels on items that they assume to measure expected outcomes. However, in such a situation, one would have expected this effect to occur not only with regard to automatic regulation but also or even more so with regard to deep acting (as it measures somebody's goodwill, in terms of intention and effort to regulate emotions). Furthermore, it is difficult to explain the systematic increase in automatic regulation and decrease in deep acting over the course of the last 4 days with such an expectation bias that should have led to higher overall levels of deep acting and automatic regulation. Ultimately, however, we cannot rule out that an expectation bias may have occurred because our design did not involve an active control group receiving an alternative treatment.

Nearly a decade ago, Bono and Vey (2005) argued that to advance emotional labor research, more experience sampling and experimental studies are necessary. The present study combined both elements in a single study. In doing so, it allowed us responding to recent calls to scrutinize the causal nature of the emotion regulation-tip relationship (Chi et al., 2011).

\section{Overall Discussion}

Overall, our findings lend support to the EASI model which suggests that emotions and emotional expressions do not only serve intraindividual functions, but that they govern social interactions and have the power to influence other individuals' behavior. Specifically, our findings show that the way in which individuals regulate emotions at work pays off financially. Study 1 sought to establish the relationship of deep acting and automatic regulation with customer tips. Future research may scrutinize the mechanisms driving this relationship. In doing so, researchers may not only consider mechanisms suggested in the EASI model, but also alternative explanations. For instance, according to equity theory (Adams, 1965; Walster, Berscheid, \& Walster, 1973), individuals seek to maintain equity between inputs and outputs in social relationships. Customers may experience more psychological pressure to reciprocate with a larger tip when being served by an employee displaying authentic emotions. Furthermore, attributions may play a role. Customers may perceive employees who display authentic positive emotions to be intrinsically motivated to help and to provide good service which may foster the wish to reward them with a larger tip.

To our knowledge, Study 1 is the first to show that deep acting and automatic regulation are both meaningfully related to real customer behavior at an intraindividual level of analysis. It thereby adds to previous research showing that between-person differences in deep acting are related to customer service evaluations, customers' behavioral intentions, and customer tips (Chi et al., 2011; Grandey et al., 2005; Pugh, 2001). Seeking to respond to repeated calls to establish causality in emotional labor research in an ecologically valid environment (Bono \& Vey, 2005; Chi et al., 2011; Grandey, 2003; Scott \& Barnes, 2011), we designed Study 2. In doing so, we were able to show that providing service employees with a training in cognitive change and attentional deployment results in an increase in customer tips. This effect seems to have been driven by automatic regulation but further research is needed to pinpoint the underlying mechanisms.

Employees who regulate their emotions with deep acting and automatic regulation are financially rewarded for their goodwill and effort by earning a higher tip. It is noteworthy that customers, who are typically motivated to obtain goods and services for the lowest price possible, make voluntary payments after having received a service (Lynn \& McCall, 2000). Our findings show that these voluntary payments are not simply reflections of social norms to leave a certain percentage of the bill as a tip, but that they are dependent on employees' service behavior. This suggests that employees' use of regulation strategies is associated with customers' willingness to spend more money. Successful emotion regulation may thus not only pay off for the employees but also for the organization: Customers who are willing to pay an extra large tip are likely to be satisfied with the service, purchase more goods, and return more often to a store. Future research may test this assumption by extending our research to other types of actual customer behavior.

\section{Limitations and Strengths}

Although the combination of our studies has a number of strengths, it also has some limitations which should be considered when drawing conclusions from the present findings. Both studies were based on relatively small samples of participants. In the first study, however, we were interested in the relationship between daily emotion regulation and daily customer tips. Therefore, we 
based our analysis on a sample of 166 daily reports which provided us with sufficient power to test our hypotheses.

To our knowledge, Study 2 is one of the first experimental field studies to investigate the effectiveness of training service workers in emotion regulation strategies. Such a set-up does not only allow making important practical implications but also has the potential to draw causal conclusions. Results revealed that the training resulted in a significant increase in the amount of tips received in the intervention group compared to the control group. Yet, the fact that the intervention did not have an effect on self-reported deep acting and that the effect on automatic regulation only emerged when considering intervention compliance, limits the possibility to attribute intervention effects on deep acting and automatic regulation. However, the emotion regulation intervention was theoretically grounded in the emotion regulation literature and closely aligned with what this literature suggests to be the essence of deep acting and automatic regulation, namely cognitive change and attentional deployment (e.g., Beal \& Trougakos, 2013; Grandey, 2000; Groth et al., 2009; Mikolajczak et al., 2009; Totterdell \& Holman, 2003). This supports the content validity of the intervention. Future research may follow up on our study by using more extended manipulation checks, for instance, by complementing traditional self-report measures of deep acting and automatic regulation with more direct measures of emotion regulation strategies (i.e., cognitive change and attentional deployment), or by using observer-ratings.

\section{Practical Implications}

The present study has important practical implications, for customer service employees as well as for organizations. Our findings suggest that both organizations and individual employees can benefit from using appropriate emotion regulation strategies at work. Previous work has suggested that in contrast to surface acting, deep acting and automatic regulation are not associated with ill-being and impaired health (Hülsheger \& Schewe, 2011; Martinez-Inigo et al., 2007). The present findings further suggest that if tips are an indicator of customer satisfaction, customers who are served by employees who engage in deep acting and automatic regulation tend to be more satisfied with the service than customers who are served by employees who do not. Organizations are consequently well advised to foster effective emotion regulation in their organizations which allows them to maintain employee health and well-being and increase performance at the same time.

Given the present findings, organizations may consider making an effort to train employees in emotion regulation strategies. Ever since studies on emotional labor have appeared in the literature, researchers have stressed the need to develop trainings and interventions in favorable emotion regulation strategies (e.g., Ashforth \& Humphrey, 1993; Grandey, 2003; Hennig-Thurau et al., 2006; Yanchus, Eby, Lance, \& Drollinger, 2010). To date, however, research on the development and evaluation of such interventions has been scarce (for an exception see Richard, 2003). Recently, Hülsheger and colleagues (2013) showed that a mindfulness intervention is effective in reducing employees' use of surface acting and thereby leads to lower levels of emotional exhaustion and more job satisfaction. Study 2 adds to this line of research by suggesting a time- and cost-effective way to enhance emotion regulation skills in customer service employees by providing them with written instructions, brief daily exercises, and reflective assignments on cognitive change and attentional deployment. The methods we applied to train emotion regulation skills in the intervention group may be considered a first step toward creating a workplace intervention. Yet, much more research is needed before this or similar interventions may be used in practice: For instance, the effectiveness of the intervention may be evaluated for other kinds of jobs, such as teachers or health care professionals. Furthermore, it is necessary to test whether such an intervention has sustainable effects that reach beyond the course of 10 days when employees don't receive daily reminders anymore. It may also be important to investigate whether the positive effects are mostly driven by cognitive change or by attentional deployment. Most importantly, however, potential effects of such an intervention on employee health and well-being need to be explored.

\section{Conclusion}

The present work deepens extant knowledge on the work-related outcomes of emotional labor. First, Study 1 revealed that deep acting and automatic regulation are meaningfully related to customer tips. Second, by adopting a diary design, our research responded to recent calls to shift the focus to the fleeting aspects of emotions and performance and investigate short-term, withinperson relationships between emotional labor and performance outcomes (Judge et al., 2009). Finally, Study 2 has important practical implications in that it provides initial evidence that emotion regulation can be influenced with a relatively brief and costeffective self-training approach.

\section{References}

Adams, J. S. (1965). Inequity in social exchange. In L. Berkowitz (Ed.), Advances in experimental social psychology (pp. 267-299). New York, NY: Academic Press.

Anseel, F., Lievens, F., Scholleart, E., \& Choragwicka, B. (2010). Response rates in organizational science, 1995-2008: A meta-analytic review and guidelines for survey researchers. Journal of Business and Psychology, 25, 335-349. http://dx.doi.org/10.1007/s10869-010-9157-6

Ashforth, B. E., \& Humphrey, R. H. (1993). Emotional labor in service roles: The influence of identity. The Academy of Management Review, $18,88-115$.

Baumeister, R. F., Bratslavsky, E., Muraven, M., \& Tice, D. M. (1998). Ego depletion: Is the active self a limited resource? Journal of Personality and Social Psychology, 74, 1252-1265. http://dx.doi.org/10.1037/ 0022-3514.74.5.1252

Beal, D. J., \& Trougakos, J. P. (2013). Episodic intrapersonal emotion regulation: Or, dealing with life as it happens. In A. A. Grandey, J. M. Diefendorff, \& D. E. Rupp (Eds.), Emotional labor in the 21st century: Diverse perspectives on the psychology of emotion regulation at work (pp. 31-55). New York, NY: Routledge.

Bliese, P. D. (2000). Within-group agreement, non-independence, and reliability: Implications for data aggregation and analysis. In K. J. Klein \& S. W. J. Kozlowski (Eds.), Multilevel theory, research, and methods in organizations: Foundations, extensions, and new directions (pp. 349381). San Francisco, CA: Jossey-Bass.

Bliese, P. D., \& Hanges, P. J. (2004). Being both too liberal and too conservative: The perils of treating grouped data as though they were independent. Organizational Research Methods, 7, 400-417. http://dx .doi.org/10.1177/1094428104268542

Bliese, P. D., \& Ployhart, R. E. (2002). Growth modeling using random coefficient models: Model building, testing, and illustrations. Organiza- 
tional Research Methods, 5, 362-387. http://dx.doi.org/10.1177/ 109442802237116

Bono, J. E., \& Vey, M. A. (2005). Toward understanding emotional management at work: A quantitative review of emotional labor research. In C. E. Hartel, W. J. Zerbe, \& N. M. Ashkanasy (Eds.), Emotions in organizational behavior (pp. 213-233). Mahwah, NJ: Erlbaum Publishers.

Brotheridge, C. M., \& Lee, R. T. (2003). Development and validation of the Emotional Labour Scale. Journal of Occupational and Organizational Psychology, 76, 365-379. http://dx.doi.org/10.1348/ 096317903769647229

Chi, N.-W., Grandey, A. A., Diamond, J. A., \& Krimmel, K. R. (2011). Want a tip? Service performance as a function of emotion regulation and extraversion. Journal of Applied Psychology, 96, 1337-1346. http://dx .doi.org/10.1037/a0022884

Cook, T. D., \& Campbell, D. T. (1979). Quasi-experimentation: Design \& analysis issues for field settings. Boston, MA: Houghton Mifflin.

Cropanzano, R., Weiss, H. M., \& Elias, S. M. (2004). The impact of display rules and emotional labor on psychological well-being at work. In P. L. Perrewe \& D. C. Ganster (Eds.), Emotional and physiological processes and positive intervention strategies (pp. 45-89). Amsterdam, The Netherlands: Elsevier.

Diefendorff, J. M., Croyle, M. H., \& Gosserand, R. H. (2005). The dimensionality and antecedents of emotional labor strategies. Journal of Vocational Behavior, 66, 339-357. http://dx.doi.org/10.1016/j.jvb.2004 .02 .001

Enders, C. K., \& Tofighi, D. (2007). Centering predictor variables in cross-sectional multilevel models: A new look at an old issue. Psychological Methods, 12, 121-138. http://dx.doi.org/10.1037/1082-989X.12 .2 .121

Gallo, I. S., Keil, A., McCulloch, K. C., Rockstroh, B., \& Gollwitzer, P. M. (2009). Strategic automation of emotion regulation. Journal of Personality and Social Psychology, 96, 11-31. http://dx.doi.org/10.1037/ a0013460

Goldberg, L. S., \& Grandey, A. A. (2007). Display rules versus display autonomy: Emotion regulation, emotional exhaustion, and task performance in a call center simulation. Journal of Occupational Health Psychology, 12, 301-318. http://dx.doi.org/10.1037/1076-8998.12.3.301

Grandey, A. A. (2000). Emotion regulation in the workplace: A new way to conceptualize emotional labor. Journal of Occupational Health Psychology, 5, 95-110. http://dx.doi.org/10.1037/1076-8998.5.1.95

Grandey, A. A. (2003). When "the show must go on:" Surface acting and deep acting as determinants of emotional exhaustion and peer-rated service delivery. Academy of Management Journal, 46, 86-96. http:// dx.doi.org/10.2307/30040678

Grandey, A. A., Fisk, G. M., Mattila, A. S., Jansen, K. J., \& Sideman, L. A. (2005). Is "service with a smile" enough? Authenticity of positive displays during service encounters. Organizational Behavior and $\mathrm{Hu}$ man Decision Processes, 96, 38-55. http://dx.doi.org/10.1016/j.obhdp .2004 .08 .002

Gross, J. J. (1998). Antecedent- and response-focused emotion regulation: Divergent consequences for experience, expression, and physiology. Journal of Personality and Social Psychology, 74, 224-237. http://dx .doi.org/10.1037/0022-3514.74.1.224

Gross, J. J. (2008). Emotion regulation. In M. Lewis, J. M. Haviland-Jones, \& L. F. Barrett (Eds.), Handbook of emotions (3rd ed., pp. 497-512). New York, NY: Guilford Press.

Groth, M., Hennig-Thurau, T., \& Walsh, G. (2009). Customer reactions to emotional labor: The roles of employee acting strategies and customer detection accuracy. Academy of Management Journal, 52, 958-974. http://dx.doi.org/10.5465/AMJ.2009.44634116

Hennig-Thurau, T., Groth, M., Paul, M., \& Gremler, D. D. (2006). Are all smiles created equal? How emotional contagion and emotional labor affect service relationships. Journal of Marketing, 70, 58-73. http://dx.doi .org/10.1509/jmkg.70.3.58

Hochschild, A. R. (1983). The managed heart. Berkeley, CA: University of California Press

Holman, D., Martinez-Iñigo, D., \& Totterdell, P. (2008). Emotional labour, well-being and performance. In C. L. Cooper \& S. Cartwright (Eds.), The Oxford handbook of organizational well-being (pp. 331-355). Oxford, UK: Oxford University Press.

Hox, J. (2002). Multilevel analysis: Techniques and applications. Mahwah, NJ: Erlbaum.

Hülsheger, U. R., Alberts, H. J. E. M., Feinholdt, A., \& Lang, J. W. B. (2013). Benefits of mindfulness at work: The role of mindfulness in emotion regulation, emotional exhaustion, and job satisfaction. Journal of Applied Psychology, 98, 310-325. http://dx.doi.org/10.1037/ a0031313

Hülsheger, U. R., Lang, J. W. B., \& Maier, G. W. (2010). Emotional labor, strain, and performance: Testing reciprocal relationships in a longitudinal panel study. Journal of Occupational Health Psychology, 15, 505521. http://dx.doi.org/10.1037/a0021003

Hülsheger, U. R., \& Schewe, A. F. (2011). On the costs and benefits of emotional labor: A meta-analysis of three decades of research. Journal of Occupational Health Psychology, 16, 361-389. http://dx.doi.org/10.1037/ a0022876

Judge, T. A., Woolf, E. F., \& Hurst, C. (2009). Is emotional labor more difficult for some than for others? A multilevel, experience-sampling study. Personnel Psychology, 62, 57-88. http://dx.doi.org/10.1111/j .1744-6570.2008.01129.x

Kanfer, R., \& Ackerman, P. L. (1989). Motivation and cognitive abilities: An integrative/aptitude treatment interaction approach to skill acquisition. Journal of Applied Psychology, 74, 657-690. http://dx.doi.org/ 10.1037/0021-9010.74.4.657

Kruml, S. M., \& Geddes, D. (2000). Exploring the dimensions of emotional labor. Management Communication Quarterly, 14, 8-49. http://dx.do org/10.1177/0893318900141002

Lang, J. W. B., \& Lang, J. (2010). Priming competence diminishes the link between cognitive test anxiety and test performance. Implications for the interpretation of test scores. Psychological Science, 21, 811-819. http:// dx.doi.org/10.1177/0956797610369492

Lazarus, R. S., \& Follkman, S. (1984). Stress, appraisal, and coping. New York, NY: Springer.

Lynn, M., \& McCall, M. (2000). Gratitude and gratuity: A meta-analysis of research on the service-tipping relationship. The Journal of SocioEconomics, 29, 203-214. http://dx.doi.org/10.1016/S1053-5357(00) $00062-7$

Martinez-Inigo, D., Totterdell, P., Alcover, C., \& Holman, D. (2007). Emotional labour and emotional exhaustion: Interpersonal and intrapersonal mechanisms. Work and Stress, 21, 30-47. http://dx.doi.org/10.1080/ 02678370701234274

Mauss, I. B., Bunge, S., \& Gross, J. J. (2007). Automatic emotion regulation. Social and Personality Psychology Compass, 1, 146-167. http:// dx.doi.org/10.1111/j.1751-9004.2007.00005.x

Mauss, I. B., Bunge, S. A., \& Gross, J. J. (2008). Culture and automatic emotion regulation. In S. Ismer, S. Jung, S. Kronast, C. van Scheve, \& M. Vanderkerckhove (Eds.), Regulating emotions: Social necessity and biological inheritance (pp. 39-60). London, UK: Blackwell. http://dx doi.org/10.1002/9781444301786.ch2

Mauss, I. B., Evers, C., Wilhelm, F. H., \& Gross, J. J. (2006). How to bite your tongue without blowing your top: Implicit evaluation of emotion regulation predicts affective responding to anger provocation. Personality and Social Psychology Bulletin, 32, 589-602. http://dx.doi.org/ 10.1177/0146167205283841

Mikolajczak, M., Tran, V., Brotheridge, C. M., \& Gross, J. J. (2009). Using an emotion regulation framework to predict the outcomes of emotional 
labor. In N. M. Ashkanasy, W. J. Zerbe, \& C. E. J. Härtel (Eds.), Research on emotion in organizations: Emotions in groups, organizations and cultures (pp. 245-273). Bingley, UK: Emerald.

Muraven, M., Tice, D. M., \& Baumeister, R. F. (1998). Self-control as limited resource: Regulatory depletion patterns. Journal of Personality and Social Psychology, 74, 774-789. http://dx.doi.org/10.1037/00223514.74.3.774

Pinheiro, J. C., \& Bates, D. M. (2000). Mixed-effects models in $S$ and S-PLUS. New York, NY: Springer. http://dx.doi.org/10.1007/978-14419-0318-1

Pugh, S. D. (2001). Service with a smile: Emotional contagion in the service encounter. Academy of Management Journal, 44, 1018-1027. http://dx.doi.org/10.2307/3069445

Rafaeli, A., \& Sutton, R. I. (1987). Expression of emotion as part of the work role. The Academy of Management Review, 12, 23-37.

Richard, E. M. (2003). Applying appraisal theories of emotion to the concept of emotional labor. (Unpublished doctoral dissertation). Louisiana State University, Baton Rouge, LA.

Rupp, D. E., McCance, A. S., Spencer, S., \& Sonntag, K. (2008). Customer (in)justice and emotional labor: The role of perspective taking, anger, and emotional regulation. Journal of Management, 34, 903-924. http:// dx.doi.org/10.1177/0149206307309261

Schreurs, B., Guenter, H., Hülsheger, U., \& van Emmerik, H. (2014). The role of punishment and reward sensitivity in the emotional labor process: A within-person perspective. Journal of Occupational Health Psychology, 19, 108-121. http://dx.doi.org/10.1037/a0035067

Scott, B. A., \& Barnes, C. M. (2011). A multilevel field investigation of emotional labor, affect, work withdrawal, and gender. The Academy of Management Journal, 54, 116-136. http://dx.doi.org/10.5465/AMJ .2011 .59215086

Sitzmann, T., \& Ely, K. (2010). Sometimes you need a reminder: The effects of prompting self-regulation on regulatory processes, learning, and attrition. Journal of Applied Psychology, 95, 132-144. http://dx.doi .org/10.1037/a0018080

Thoresen, C. J., Bradley, J. C., Bliese, P. D., \& Thoresen, J. D. (2004). The big five personality traits and individual job performance growth trajectories in maintenance and transitional job stages. Journal of Applied Psychology, 89, 835-853. http://dx.doi.org/10.1037/0021-9010.89.5 .835

Totterdell, P., \& Holman, D. (2003). Emotion regulation in customer service roles: Testing a model of emotional labor. Journal of Occupational Health Psychology, 8, 55-73. http://dx.doi.org/10.1037/10768998.8.1.55

Totterdell, P., \& Parkinson, B. (1999). Use and effectiveness of selfregulation strategies for improving mood in a group of trainee teachers.
Journal of Occupational Health Psychology, 4, 219-232. http://dx.doi .org/10.1037/1076-8998.4.3.219

Trautwein, U., Lüdtke, O., Marsh, H. W., Köller, O., \& Baumert, J. (2006) Tracking, grading and student motivation: Using group composition and status to predict self-concept and interest in ninth-grade mathematics. Journal of Educational Psychology, 98, 788-806. http://dx.doi.org/ 10.1037/0022-0663.98.4.788

Trougakos, J. P., Hideg, I., Cheng, B. H., \& Beal, D. J. (2014). Lunch breaks unpacked: The role of autonomy as a moderator of recovery during lunch. Academy of Management Journal, 57, 405-421. http://dx doi.org/10.5465/amj.2011.1072

Tsai, W. C., \& Huang, Y. M. (2002). Mechanisms linking employee affective delivery and customer behavioral intentions. Journal of Applied Psychology, 87, 1001-1008. http://dx.doi.org/10.1037/0021-9010 87.5.1001

Van Kleef, G. A. (2009). How emotions regulate social life: The emotions as social information (EASI) model. Current Directions in Psychological Science, 18, 184-188. http://dx.doi.org/10.1111/j.1467-8721.2009 .01633.x

Van Kleef, G. A., De Dreu, C. K. W., \& Manstead, A. S. R. (2010). An interpersonal approach to emotion in social decision making: The emotions as social information model. Advances in Experimental Social Psychology, 42, 45-96. http://dx.doi.org/10.1016/S0065-2601(10) 42002-X

Walster, E., Berscheid, E., \& Walster, G. W. (1973). New directions in equity research. Journal of Personality and Social Psychology, 25, 151-176. http://dx.doi.org/10.1037/h0033967.

West, S. G., Aiken, L. S., \& Krull, J. L. (1996). Experimental personality designs: Analyzing categorical by continuous variable interactions. Journal of Personality, 64, 1-48. http://dx.doi.org/10.1111/j.1467-6494 1996.tb00813.x

Yanchus, N. J., Eby, L. T., Lance, C. E., \& Drollinger, S. (2010). The impact of emotional labor on work-family outcomes. Journal of Vocational Behavior, 76, 105-117. http://dx.doi.org/10.1016/j.jvb.2009.05 .001

Zapf, D. (2002). Emotion work and psychological well-being: A review of the literature and some conceptual considerations. Human Resource Management Review, 12, 237-268. http://dx.doi.org/10.1016/S10534822(02)00048-7

Received March 20, 2011

Revision received August 27, 2014 Accepted September 19, 2014 